\title{
UTOPIAS LINGUISTIICAS'
}

\author{
LINGUISTIC UTOPIAS
}

\section{Mary Louise Pratt ${ }^{*}$ \\ Tradução de André M. do Nascimento e Joana Plaza Pinto**}

\begin{abstract}
RESUMO
Este artigo, publicado originalmente em uma coletânea em 1987, aborda criticamente a noção de "comunidade linguística" em diferentes abordagens dos estudos da linguagem, do Gerativismo à Análise do Discurso, passando pela Sociolinguística e pela Crítica Literária. Discutindo a distância entre a homogeneidade da comunidade linguística imaginada (no sentido de Anderson) e a realidade fraturada da experiência linguística nas sociedades modernas estratificadas, este texto propõe uma mudança de abordagem para os estudos da linguagem, defende o fim das utopias linguísticas e o reconhecimento urgente de uma linguística do contato.

Palavras-chave: comunidade linguística; comunidade imaginada; contato.
\end{abstract}

\section{ABSTRACT}

Originally published in a collection in 1987, this article provides a critical discussion of the notion of "linguistic community" in different approaches of language studies, from Generative Theory to Discourse Analysis, including Sociolinguistics and Literary Criticism. In a debate about the distance between the homogeneity of the imagined linguistic community (in Anderson's sense) and the fractured reality of linguistic experience in modern stratified societies, the text proposes a change in the approach to language studies and advocates the end of linguistic utopias, as well as the urgent recognition of a linguistics of contact.

Keywords: linguistic community; imagined community; contact.

Estamos no processo de criar uma nova civilização na qual, pela primeira vez, gente de todo lugar está começando a participar dos eventos que estão moldando nosso futuro comum. A realização do

\footnotetext{
* Department of Social and Cultural Analysis. Department of Spanish and Portuguese. Center for Latin American and Caribbean Studies. New York University. marylouise.pratt@nyu.edu

"* UFG, Goiânia (GO), Brasil. marquesandre@yahoo.com.br; UFG, Goiânia (GO), Brasil. joplazapinto@gmail.com

${ }^{1}$ Artigo reproduzido em Nigel Fabb et al (ed.), The linguistics of writing: arguments between language and literature. New York: Nethuen Inc., p. 48-66, 1987, com a permissão da autora.

N.T.: Em 1987, quando Pratt publicou este texto pela primeira vez, o Apartheid não tinha ainda sido abolido na África do Sul, por isso a autora escreve ainda no presente. O fim deste regime ocorreu oficialmente somente seis anos depois, em 1994.
} 
sonho da comunicação em âmbito mundial e a crença crescente de que os homens podem planejar para mudar estão abrindo novas potencialidades para as relações humanas.

(Margaret Mead, "One world, but which language?" Redbook Magazine, abril de 1966)

Uma língua que funciona foi moldada por homens e mulheres, gente velha e criancinhas, gente inteligente e ignorante, gente com boa memória e gente com pouca memória, aquelas/es que prestam atenção à forma e aquelas/es que prestam atenção ao som, e por gente com toda a diversidade de interesses presentes em sua cultura através das gerações. Essa mesma multiplicidade de falantes cria a redundância que torna a língua flexível e inteligível para todos os diferentes tipos de gente que são suas/seus falantes em qualquer momento. (ibid.)

Em 4 de julho de 1986, enquanto este texto estava sendo elaborado, uma enorme celebração foi realizada nos Estados Unidos para comemorar o centenário da Estátua da Liberdade. "Incluirá", exultava o Times londrino (2 de julho de 1986), "60.000 barcos no Porto de Nova Iorque, 3.100 jantares por $\$ 5.000$ o prato, 22 dos veleiros mais altos do mundo em desfile, 76 trombones de toda a América na banda marcial universitária, 300 dançarinas de jazz em malhas próprias, 150 violinistas, 200 dançarinos sósias de Elvis Presley e o maior show de fogos de artifício já montado". Na ocasião, alguém poderia ser tentado a empreender uma análise neopoética do evento - como em uma simulação baudrillardiana reencenando uma forma perdida de patriotismo, ou como um próximo passo na elevação do alto consumo e dos meios de comunicação de massa ao status de cultura oficial, ou talvez como a mais grandiosa projeção do princípio da equivalência do eixo de seleção no eixo de combinação.

Para meus propósitos aqui, no entanto, foi mais útil relembrar a cerimônia original de inauguração da Estátua da Liberdade cem anos antes. Naquela ocasião, de acordo com a historiadora Leslie Allen (1985), um número considerável de homens dignitários e duas ou três de suas esposas se reuniram ao redor da base da estátua para realizar a cerimônia oficial, enquanto integrantes da Associação pelo Sufrágio das Mulheres da Cidade de Nova Iorque rodeavam a ilha num barco alugado protestando contra o evento. Num pronunciamento emitido à parte, as sufra- 
gistas se declararam escarnecidas com o fato de a estátua de uma mulher ser erguida para simbolizar a liberdade em um país no qual as mulheres não tinham sequer os mínimos direitos políticos.

\section{A COMUNIDADE IMAGINADA}

Eu gostaria de reter essa imagem da estátua cercada por homens dignitários cercados por mulheres sufragistas, como uma imagem paródica de um tipo de linguística sobre a qual eu me proponho falar aqui sob o rótulo de "linguística da comunidade". Essa locução destina-se a ressaltar uma dimensão utópica compartilhada por boa parte da linguística moderna, incluindo o que às vezes é chamado de suas vertentes "críticas". Uso aqui o termo comunidade no interessante sentido proposto por Benedict Anderson em seu livro Imagined Communities: Reflections on the Origin and Spread of Nationalism (1983). Anderson observa que, com a possível (apenas possível) exceção dos "povoados primordiais de contato face-a-face", comunidades humanas existem como entidades imaginadas nas quais as pessoas "nunca conhecerão a maioria de seus membros, nunca os encontrarão ou mesmo ouvirão, ainda que nas mentes de cada um viva a imagem de sua comunhão". "As comunidades são distinguidas", continua Anderson, "não pela sua falsidade/autenticidade, mas pelo estilo em que são imaginadas. Aldeãos javaneses sempre souberam que estão conectados a pessoas que nunca viram, mas esses laços foram outrora inventados de forma bem particular - como redes indefinidamente extensíveis de parentesco e clientela. Até muito recentemente, a língua javanesa não tinha qualquer palavra que significasse a abstração "sociedade" (p. 15).

O que surgiu "muito recentemente" foi, naturalmente, o Estado-nação moderno, uma comunidade imaginada em cujas origem e natureza Anderson está particularmente interessado. Ele propõe três aspectos que caracterizam o "estilo" no qual a nação moderna é imaginada. Primeiro, ela é imaginada como limitada por "fronteiras finitas, embora flexíveis"; segundo, é imaginada como soberana; e terceiro, é imaginada como comunidade, uma "profunda camaradagem horizontal", uma "fraternidade". "Em última instância", diz Anderson, "é essa fraternidade [a generificação do termo parece intencional] que torna possível, ao longo dos últimos dois séculos, para muitos milhões de pessoas, não tanto matar como voluntariamente morrer por imaginações tão limitadas" (p.16). Como essa imagem sugere, a naçãocomunidade é corporificada metonimicamente na pessoa finita, soberana e fraterna do cidadão-soldado. 
Anderson acredita que as burguesias europeias são notáveis por sua habilidade de "conseguir solidariedade numa base essencialmente imaginada" (p. 74) numa escala muito maior do que as elites anteriores. A literatura e a linguística da escrita desempenham um papel central em seu argumento. Anderson sustenta, como outros/as sustentaram, que o principal instrumento que tornou possível os projetos burgueses de construção da nação foi o capitalismo editorial. A circulação comercial de livros nos diferentes vernáculos impressos, ele argumenta, foi o que primeiro criou as redes elitistas invisíveis que, ao final, constituiriam a si mesmas e àquelas/ es a quem dominavam nações. (As estimativas são que 180 milhões de livros foram postos em circulação na Europa apenas entre os anos de 1500 e 1600). No século XVIII, floresceu o romance e o jornal e duas "formas de imaginar" que "forneceram os meios técnicos para 're-presentar' o tipo de comunidade imaginada que é a nação" (p.30). Essas duas formas impressas apresentam mundos nos quais múltiplos enredos são seguidos descontínua e simultaneamente, conectados apenas por sua adjacência e totalizados nas imaginações de narradoras/es oniscientes ou leitoras/es.

Ora, Anderson não ressalta esse ponto, mas as três características que menciona - limitação, soberania e comunidade - tornam claro que o "estilo de imaginar" das nações modernas é fortemente utópico. Digo isso tanto no sentido estrito de que são imaginadas como ilhas, como entidades sociais discretas e soberanas, como no sentido mais geral de que a versão imaginada é uma idealização, corporificando valores como fraternidade, igualdade ou liberdade, que as sociedades professam, mas, como ressaltavam as sufragistas, falharam completamente em realizar.

Esse protótipo da nação moderna como comunidade imaginada está, gostaria de sugerir, refletido no objeto de estudo imaginado da linguística: a comunidade de fala. Em outras palavras, a fraternidade limitada, soberana e horizontal de Anderson é a imagem através da qual a comunidade de fala frequentemente é concebida na linguística moderna. De fato, faz sentido ver uma boa dose de descrição linguística, dos tipos crítico e "acrítico", como engajada na produção dessa entidade utópica imaginada. Muitas/os críticas/os têm ressaltado a forma como nossa linguística moderna da língua, do código e da competência postula um mundo social unificado e homogêneo no qual a língua existe como um patrimônio compartilhado - mais precisamente, como um dispositivo para imaginar comunidade. O caso prototípico ou não marcado de língua é geralmente assumido na linguística como a fala face-a-face de falantes nativos adultos (como no diagrama de Saussure) em situações monolíngues, ou mesmo monodialetais - em resumo, o caso maximamente homogêneo linguística e socialmente. Essa é a situação em que os dados são sentidos como "mais puros", na qual você pode ver mais claramente os fundamentos de como a 
língua funciona, com a mínima distorção, infelicidade ou "ruído". Ora, certamente poder-se-ia imaginar uma teoria linguística que assumisse coisas diferentes - que defendesse, por exemplo, que a melhor situação de fala para a pesquisa linguística fosse aquela envolvendo, por exemplo, uma sala cheia de pessoas em que cada uma falasse duas línguas e compreendesse uma terceira, e que tivesse apenas uma língua em comum com qualquer uma das outras pessoas. Um coquetel da ONU, talvez, ou um julgamento na África do Sul contemporânea. Aqui, talvez se argumentasse, é onde você mais prontamente pode ver como a língua funciona - isso depende de quais funcionamentos você quer ver ou quer ver primeiro.

Por trás da Langue, por trás do diagrama de Saussure, está em pé a imagem da comunidade imaginada moderna: discreta, soberana, fraterna - uma utopia linguística. Na tradição chomskyana, um objeto de estudo maximamente homogêneo é alcançado no construto do falante ideal de cuja competência a teoria deve dar conta, enquanto a "camaradagem profunda e horizontal" da qual fala Anderson está corporificada na ideia de competência como um recurso inato e discreto que todos os seres humanos compartilham. Embora o falante ideal seja uma abstração, isso (ele) não pode em princípio ser caracterizado ou mesmo concebido em um estilo socialmente neutro. Assim, por exemplo, na gramática formal, variedades padrão nacionais continuam a funcionar como padrões, definindo a problemática da fonologia, da negação ou da quantificação, e assim por diante. A distância entre langue e parole, competência e desempenho, é a distância entre a homogeneidade da comunidade imaginada e a realidade fraturada da experiência linguística nas sociedades estratificadas modernas.

\section{2. "COMUNIDADE" EM DISCURSO}

Embora mais proximamente ligadas à interação social, também a pragmática e a teoria do discurso muitas vezes produzem língua segundo a imagem da comunidade imaginada. Trabalho em pragmática e inferência assume a existência de princípios de cooperação e homogeneidade correspondentes à "camaradagem profunda e horizontal" de que Anderson fala. Em versões padrão da teoria dos atos de fala, as condições preparatórias para os atos de fala incluem condições de formular entendimento compartilhado sobre quem quer ou precisa dizer o que, e condições de que ambas/os as/os falantes compartilham a mesma competência na única língua em uso. Pesquisa sobre interação na conversação, nas salas de aula, nos ambientes médicos, e assim por diante, tende esmagadoramente a apresentar os intercâmbios 
em termos de conjuntos únicos de regras e entendimentos compartilhados, e a ordenação que eles produzem. Desordens (como os barcos cheios de sufragistas) são quase automaticamente vistas como falhas ou desarranjos que não devem ser levados em consideração dentro do sistema. Modelos envolvendo jogos e jogadas são frequentemente usados para descrever a interação e preservam o sentido de opções finitas, a presença de fronteiras, regras compartilhadas entre jogadores iguais. Apesar de quaisquer diferenças sociais que possam estar em funcionamento, é suposto que todas/os as/os participantes estão engajadas/os no mesmo jogo e que o jogo é o mesmo para todas/os as/os jogadoras/es.

Talvez mais importante, nesses modelos-jogos, somente jogadas legítimas são nomeadas no sistema, no qual "legítimo" é definido do ponto de vista do grupo em posição de autoridade. Linguagem professora/or-estudante, por exemplo, tende a ser descrita quase inteiramente do ponto de vista da/o professora/or. De acordo com uma posição padrão, "interação verbal dentro da sala de aula difere marcadamente da conversação inconstante na medida em que seu propósito principal é instruir e informar" (COULTHARD 1977, p. 101). O ponto de referência aqui é obviamente ensinar, não "alunar" (o termo nem mesmo existe) - de fato, alunas/os não estão sequer presentes conceitualmente nessa formulação, apesar da sua menção à interação. A taxonomia padrão de Flanders para o discurso de sala de aula postula sete tipos discursivos para professoras/es, enquanto para alunas/os há apenas as duas categorias sem conteúdo: "iniciar" e "responder" (ver COULTHARD 1977; COULTHARD \& MONTGOMERY 1981).

Em outras palavras, estudantes estão presentes somente quando são interpeladas/os diretamente por professoras/es, e mesmo assim de uma maneira reduzida e idealizada. Paródias, recusas, rebeliões e assim por diante caem fora da descrição, e com elas as lutas pela disciplina que são uma parte tão fundamental do processo escolar ("Obviamente", lemos em uma descrição, "é preciso haver alguma etiqueta linguística dentro da sala de aula... Há várias maneiras por meio das quais professoras/es decidem quem vai falar." COULTHARD \& MONTGOMERY 1981, p. 9-10). O que quer que as/os estudantes possam estar fazendo umas/uns com as/os outras/os, e por mais que possam envolver as/os professoras/es nessas ações, permanece invisível, mesmo sendo uma importante dimensão do "alunar". Assim, do intercâmbio de sala de aula a seguir, o máximo que nos é dito é que representa uma instância normal do "ciclo de ensino" padrão:

P: Pode me dizer por que você come toda esta comida? Sim.

A: Para você ficar forte.

P: Para você ficar forte. Sim. Para você ficar forte. Por que você quer ser forte? 
A: Músculos, senhor.

P: Para ter músculos. Sim. Bem, o que você quer usar - o que você gostaria de fazer com seus músculos?

A: Usá-los, senhor.

(COULTHARD \& MONTGOMERY 1981, p. 5)

Muitas questões poderiam ser feitas sobre o que o aluno está fazendo nesse intercâmbio, sobre que tipo de "alunar" está ocorrendo aqui. Qual é o significado social do minimalismo das respostas em comparação com as questões? Como o aluno está se apropriando da língua da/o professora/or e se distanciando dela? Como seu discurso é generificado? Como ele está se posicionando na ordem social baseada no "alunar"? $\mathrm{O}$ ponto aqui não é que abordagens descritivas padrão sejam todas erradas, mas que elas são limitadas de maneiras que elas mesmas não reconhecem, maneiras que a linguística da comunidade torna difícil reconhecer.

Algumas vezes o impulso para unificar o mundo social e linguístico substitui outras lógicas sociais bastante convincentes. Há uma ironia, por exemplo, no pensamento de salas de aulas como estáveis, harmoniosas, arenas discursivas funcionando sem problemas, nas quais professoras/es e alunas/os continuam produzindo juntas/ os os mesmos ordenados ciclos dia após dia. Pois, de fato, as salas de aula devem ser entendidas como lugares onde as coisas mudam o tempo todo, onde alunas/os fazem e dizem coisas diferentes de um dia para outro porque a educação e a socialização estão em processo. Vê-las como comunidades no sentido que estou descrevendo, efetivamente obscurece esses processos, ou sugere que eles não estão acontecendo. A linguagem da criança, por exemplo, é comumente descrita em termos de sua progressão em direção à fala da/o adulta/o - o que significa que é analisada do ponto de vista das/os adultas/as que criam as crianças. Como seria se fosse analisada como esforços das crianças para lidar com as/os adultas/os responsáveis por elas, ou como encenações das crianças da categoria social generificada "criança", sobre a qual elas aprendem na interação com adultas/os ou assistindo a shows de muppets na TV? Afinal, é somente através da diferença em relação às crianças que adultas/os sabem que elas/os são adultas/os!

Intercâmbios médicos e burocráticos são examinados pela linguística da comunidade em moldes semelhantes. As análises tendem a serem conduzidas principalmente em termos de se o objetivo médico ou burocrático é alcançado, o que quer dizer que a análise se situa dentro das mesmas estruturas de autoridade que governam os próprios intercâmbios. Tal postura limita possibilidades de compreensão crítica - não se pode, por exemplo, facilmente distinguir cooperação de coerção, submissão ou respostas mais complexas, e de fato pode não ver necessidade de fazer tais 
distinções. Essas limitações são expostas pela discussão de Aaron Cicourel (1982) de um caso de uma mulher paciente ginecológica que expressa contínuo ceticismo sobre o diagnóstico e tratamento prescrito pelo seu médico, mesmo ela se submetendo ao tratamento (uma histerectomia). Essa situação é definida por Cicourel como anormal, já que "normalmente, a paciente seguiria os objetivos tacitamente acordados da conversação (submeter-se a uma entrevista ou exame médico), e acreditaria nos atos de fala expressos (o diagnóstico e a ação oferecida pelo médico)" (p. 72). De novo, os papéis sociais e verbais atribuídos à paciente aqui - submissão e crença - são inteiramente reativos e, de fato, não verbais. Mulheres familiarizadas com o gênero conversacional conhecido como "histórias de horror ginecológicas" vão rapidamente questionar essa norma com bases empíricas. Metodologicamente, a caracterização de Cicourel simplesmente pressupõe estruturas estabelecidas de autoridade médica e, portanto, não pode examiná-las nem questioná-las.

E questioná-las é o que ele não faz. De fato, a análise de Cicourel tem o efeito não somente de legitimar o status quo, mas de ativamente deslegitimar a crítica. $\mathrm{A}$ dificuldade entre a paciente e o médico é caracterizada como um conflito entre as "crenças" da mulher e o "conhecimento factual" do médico. A mulher é vista como continuamente incapaz ou sem vontade de "revisar suas crenças" à luz da informação que lhe é dada pelo médico, uma recalcitrância é atribuída a certas "preocupações carregadas de emoções" que ela tem a respeito da qualidade ou confiança no cuidado médico, e a certas "experiências" que ela sofreu. Por conseguinte, dois vocabulários não intercambiáveis constroem a análise: o médico tem conbecimento na forma de fatos e informaçãa; a paciente tem crenças ancoradas na emoção e na experiência. Por um lado, somos levados a perguntar por que em lugar nenhum o médico é visto como tendo suas próprias crenças que estão em jogo; por outro lado, imaginamos por que nenhuma das "experiências" da mulher é levada em conta como conbecimento ou fato (elas incluem um período de trabalho num hospital e o testemunho de má conduta médica, o fato de ter cuidado de um marido morrendo de câncer numa instalação médica militar, de ter visto um documentário de televisão sobre fraude cirúrgica, e ter sido previamente mal diagnosticada pela mesma doença por outro ginecologista).

A conclusão que Cicourel oferece é uma generalização a ser aplicada, curiosamente, a ambos pacientes médicos e sujeitos em experimentos psicológicos: cientistas precisam saber que a "base esquematizada de conhecimento" de tais pessoas inclui "um conjunto de metaproposições... dirigidas por elementos emocionais que podem levar o paciente ou sujeito a negar fatos contraditórios ou resistir a aceitá-los, ainda que revelem uma consciência deles; há uma relutância geral em revisar 
crenças à luz de nova evidência, enquanto um busca cognitiva ativa continua por nova informação que apoie as metaproposições" (p. 72). A própria análise de Cicourel, tomada como sujeito/paciente de um diagnóstico crítico, talvez convencesse alguém dessa conclusão. Ao mesmo tempo, é óbvio que, apesar da rígida intransigência das suas metaproposições e elementos emocionais, as pessoas mudam o tempo todo.

\section{3. "COMUNIDADE" COMO MACHO}

Como um todo, como o exemplo anterior pode sugerir, a linguística da comunidade tem sido também um projeto androcêntrico, relutante em abordar as diferenciações linguísticas segundo modelos de gênero. Isto tem sido um obstáculo para compreender a produção social de gênero e a reprodução social da dominação masculina - seguramente um dos projetos críticos mais urgentes e viáveis hoje disponíveis. Todas/os nós sabemos que a atividade de fala é profundamente, mesmo impiedosamente, generificada. Praticamente toda conversação ou sala de aula exibe comportamento radicalmente diferente por e para participantes masculinos e femininas. Na gramática formal, contudo, gênero é excluído juntamente com todas as outras categorias sociais. Na pragmática dominante, a marca de gênero está presente apenas implicitamente nas linhas traçadas, por exemplo, entre quais práticas linguísticas são vistas como não marcadas, bem sucedidas, aceitáveis, cooperativas, e assim por diante - o que está no sistema - e quais são marcadas, desviantes, mal sucedidas, ou de alguma outra forma problemáticas para o sistema. Aqui está, por exemplo, uma lista de práticas verbais que têm sido associadas às mulheres. Tais práticas podem ser prontamente conectadas tanto ao relativo desempoderamento das mulheres como à sua associação à esfera doméstica:

1. Plantar sugestões nas mentes de outras pessoas de modo que elas pensem que pensaram por si próprias.

2. Falar a uma pessoa de maneira que outra possa ouvir e ser afetada da forma desejada.

3. Na escrita acadêmica, construir gradualmente evidência em direção ao ponto principal, em vez de formulá-lo no início e então respaldá-lo.

4. Contar histórias como uma forma de comunicar valores (para crianças, por exemplo).

5. Fofocar como um meio de apoiar e vigiar umas as outras e como uma forma de poder sobre os homens, que temem essa rede secreta. 
6. Conversar frequentemente de forma repetitiva com outra com o propósito de manter um mundo compartilhado (conversa fiada).

7. Conversar com sujeitos que sequer conhecem língua (bebês, animais, plantas, aparelhos de $\mathrm{TV}$, as paredes). ${ }^{1}$

Não é meu propósito argumentar se essas práticas de fato são mais usadas por mulheres do que por homens - muito provavelmente não são. $\mathrm{O}$ que é de interesse é o fato de que elas são associadas às mulheres e que na pragmática hegemônica elas frequentemente caem fora do que é rotulado como comunicação normal e direta. Fofocar, por exemplo, é rotineiramente referido como violar condições de relevância ou a máxima de quantidade ou condições de felicidade, requerendo que as/os ouvintes precisem saber o que as/os falantes estão lhes contando. Contar histórias é quase sempre considerado pseudo-linguagem de algum tipo, nas quais as regras que governam a comunicação normal são de alguma forma suspensas. Plantar sugestão e outras formas de manipulação violam as condições de sinceridade da teoria dos atos de fala. Conversar com entidades não-verbais, naturalmente, viola as condições preparatórias que invocam competência compartilhada.

A marginalização das formas de fala associadas às mulheres e às esferas das mulheres é sintomática não simplesmente do androcentrismo na linguística, mas de uma extraordinária - de fato patologicamente tacanha - concepção do que seja "o sistema normal" e "a comunicação direta". Teorias rotineiramente excluem todas as formas de atividade lúdica e outras práticas comumente associadas ao cuidado, à intimidade e à socialização. Mais fora ainda da escala, assume-se, estariam as práticas tabu de protesto - demandas, queixas, interrupções, recusas. A utopia linguística, ao que parece, não é apenas uma fraternidade qualquer. Como imaginada pela gramática formal e sistêmica, parece frequentemente ser uma fraternidade de acadêmicos ou burocratas, ou talvez de máquinas falantes falando o discurso verdadeiro-falso da ciência ou a língua da racionalidade administrativa (ver, por exemplo, BACH \& HARNISH, 1979, como discutido em PRATT, 1986).

Compreende-se uma relutância particular em confrontar a questão do gênero na linguística da langue. Incluir tanto a ilha cheia de homens dignitários e o barco cheio de mulheres sufragistas na mesma imagem é introduzir, de fato, uma profunda clivagem dentro da comunidade imaginada. É trazer mesmo a classe dominante para uma zona de profunda incoerência interna e de conflito que é quase insuportável de se confrontar. Essa clivagem coloca os homens dignitários em desacordo não apenas

\footnotetext{
1 Para esses e outros exemplos, ver Lakoff (1975), Harding (1975), Hiatt (1977), Key (1977), Thorne e Henley (1975). Para visões mais contemporâneas sobre o assunto, Thorne et al. (1983); Steedman et al. (1985), Kramarae et al. (1984).
} 
com as mulheres sufragistas atrás deles, mas com as esposas aos seus lados, com a estátua diante deles e, sem dúvida, com eles próprios: por que eles escolheram celebrar seu ideal não em uma imagem de si mesmos mas de sua outra subordinada?

\section{SUBCOMUNIDADE/SUBUTOPIA}

A Sociolinguística tem frequentemente criticado as tendências de homogeneização e normalização da gramática formal e da análise do discurso, e tem situado a variabilidade social da língua no centro de sua agenda. Nas abordagens convencionais, a língua da comunidade de fala é vista como dividida em numerosos estilos (HYMES 1974, por exemplo) ou registros (HALLIDAY 1977, por exemplo) diferentes. Porém, essa insistência na heterogeneidade não significa necessariamente que a linguística da comunidade foi deixada pra trás. Estilos, registros e variedades são tipicamente tratados não como linhas que dividem a comunidade, mas como propriedade compartilhada, um repertório comunal que pertence a todas/os e que todas/os buscam usar de formas apropriadas e ordenadamente. Aqui, novamente, reconhece-se o impulso para unificar e harmonizar o mundo social, o mesmo impulso em funcionamento nos exemplos da análise do discurso discutidos anteriormente.

Esse é o momento da linguística da comunidade em que a divisão e a hierarquia sociais internas são estudadas, a escolha da/o linguista é frequentemente imaginar comunidades de fala separadas com suas próprias fronteiras, soberania, fraternidade e autenticidade. Para escolher um exemplo bem conhecido, esse é o ângulo a partir do qual William Labov (1972) representa o Inglês Negro Americano. De fato, há um sentido real no qual o conceito de Inglês Negro Vernáculo (INV) de Labov criou uma comunidade de fala ao longo das linhas utópicas às quais venho me referindo. De forma similar, alguns trabalhos feministas iniciais em linguística procuraram traçar uma entidade chamada "linguagem das mulheres". Pode-se falar aqui de uma "linguística de subcomunidades", semelhante em muitos aspectos ao trabalho etnográfico e sociológico sobre subculturas (por exemplo, Hebdige 1979, Willis 1977). Considerados como prática crítica - como linguística crítica no sentido dado por Roger Fowler e seus coautores (FOWLER et al, 1979) - os trabalhos desse tipo podem ser extraordinariamente empoderadores. De fato, desafiam a força normativa da gramática padrão, insistindo na heterogeneidade, na existência e legitimidade de estilos de vida outros que não aqueles dos grupos dominantes. Desse modo, participam diretamente, como faz o trabalho de muitas/os linguistas 
pesquisando sobre linguagem de grupos marginais ou estigmatizados, sobre a emancipação social e política desses grupos.

O que a abordagem da "subcomunidade" não faz, porém, é ver a/o dominada/o e a/o dominante nas suas relações umas/uns com as/os outras/os - essa é a limitação imposta por imaginações de comunidade. A linguística da comunidade tende a interpretar divisões sociais um pouco como a linguística do século XIX construiu diferenças dialetais, como produtos de obstáculos pré-dados para a comunicação, como rios e cadeias de montanhas. Diferença social é mais vista como constituída por distância e separação que por contato contínuo e relações estruturadas no espaço social compartilhado. A língua é vista como um nexo da identidade social, mas não como um lugar de luta social ou uma produtora de relações sociais. Como David Silverman e Brian Torode observam em The Material Word (1980), a reivindicação de Labov sobre o Inglês Negro Vernáculo na realidade sugere "não há problema aqui" ou se há problema aqui, não tem nada a ver com língua (SILVERMAN \& TORODE 1980, capítulo 8).

Como se poderia esperar dentro da linguística da comunidade, o ponto em que Labov encontra de fato um problema é na fronteira borrada onde dominada/o e dominante se encontram. Ele denuncia a fala de um falante negro de classe média, perguntado pelo entrevistador branco para dar sua visão sobre o sobrenatural. $\mathrm{O}$ falante "falha" em falar INV, e em vez disso produz o "empolado, redundante, bombástico e vazio" Inglês do americano de classe média. "No final", diz Labov, "nós não sabemos o que ele está tentando dizer, e nem ele mesmo" (1972, p. 200). Essa reação revela, sim, assustadoramente os limites de um projeto crítico fundamentado numa ideologia da autenticidade. Silverman e Torode tentam superar essa limitação, reanalisando o intercâmbio como uma intervenção da parte do falante negro no discurso dominante, implicitamente racista, introduzido pelas questões do entrevistador. A entrevista ela mesma é tratada não como uma exposição unilateral do entrevistado dos padrões de fala espontâneos da sua comunidade, mas como um encontro concreto entre dois sujeitos constituídos dentro de uma rede hierárquica e conflituosa de relações sociais na qual racismo e conflito racial são permeáveis. Esse não é o tipo de leitura que se pode fazer de dentro da linguística da comunidade.

\section{COMUNIDADE INTERPRETATIVA}

Há um paralelo interessante a ser feito aqui com a crítica literária, na qual o conceito de comunidade interpretativa tem recentemente chegado ao primeiro 
plano, um conceito em muitos aspectos modelado na comunidade de fala da linguística. Assim como algumas/uns linguistas têm lidado com a variação linguística simplesmente reimaginando a comunidade como um conjunto de subcomunidades autonomamente concebidas, algumas/uns críticas/os da estética da recepção lidam com a diversidade de interpretação postulando comunidades interpretativas separadas (FISH, 1980). Diferenças interpretativas simplesmente indicam fronteiras entre essas comunidades, novamente da mesma forma como os Pirineus dividem a Espanha da França (e o País Basco de ambas). As próprias comunidades são mais uma vez imaginadas como as nações de Anderson - fraternidades soberanas e horizontais.

Novamente, a limitação da abordagem é que as comunidades interpretativas não são vistas em suas relações e interações umas com as outras. É sintomático que a linguística das subcomunidades tipicamente busque seus dados na esfera privada, em contextos domésticos e de lazer nos quais, de fato, grupos étnicos, classes, grupos etários e assim por diante parecem mais autocontidos, sua comunicação mais homogênea. Também para a literatura, as comunidades interpretativas são concebidas no todo como entidades privatizadas, nas quais ler é uma forma de consumo de lazer, ou ao menos uma atividade sui generis conectada com nada em particular fora de si mesma (PRATT, 1982).

Em ambas as concepções linguística e literária de subcomunidade, então, prontamente se distingue a nostalgia pela totalidade perdida da comunidade mais ampla. No caso literário, a diversidade de interpretação é frequente e espontaneamente, embora de forma alguma necessariamente, percebida como falta de consenso, uma perda. E uma perda certamente houve, ou antes uma mudança. Pois, se o reconhecimento da variabilidade linguística rompe a ideia imaginada de línguas nacionais homogêneas, a variabilidade interpretativa rompe a ideia de literaturas nacionais canônicas mantidas em comum e formando o objeto do estudo literário. Literaturas nacionais motivam o que se poderia chamar de uma "crítica da comunidade", outro duradouro projeto utópico cuja tarefa tem sido proteger um patrimônio nacional ou cultura oficial. $\mathrm{Na}$ era da estética da recepção relativizante, a compreensão literária fica reconstituída como uma atividade profissional especializada, automotivada, ou, como no caso da crítica feminista e radical, uma ruptura ativa do patrimônio. A crítica da estética da recepção e seus desenvolvimentos antifundamentalistas registram, entre outras coisas, um enfraquecimento de projetos literários nacionais, um processo, por sua vez, ligado, ao que parece, a um realinhamento da própria relação da universidade com a nação, o nacionalismo e o Estado. ${ }^{2}$

2 A alegação de Hobsbawn de que "as escolas e especialmente as universidades são as vencedoras conscientes do nacionalismo" (citado em Anderson, 1983) parece não mais se aplicar nos anos 1980, mais ou menos vinte e cinco anos depois de feita. 
De fato, o próprio conceito de nação-comunidade, como uma entidade cultural e política, é desafiado pelas mudanças em larga escala nos últimos trinta anos. Econômica e politicamente, fomos informados, a ordem mundial tem se tornado cada vez mais transnacional, da mesma forma que as estruturas políticas nacionalmente fundadas continuamente se encontram desafiadas por interesses econômicos transnacionais. As lutas pela descolonização dos anos 1950 e 1960 produziram novas nações muito diferentes do modelo europeu. Muitas eram incontestavelmente multilíngues e não tinham uma candidata clara para uma língua nacional ou uma tradição artístico-literária nacional. Algumas resolveram o problema adotando línguas coloniais europeias cuja relação com a identidade nacional sempre seria problemática. Dentro das fronteiras das nações ocidentais, a imigração em grande escala, também desde a década de 1960, tem produzido nova e dramática diversidade linguística e cultural, tornando problemáticas as imaginações nacionalistas tradicionais. Dificilmente se pode ser surpreendida/o com o fato de que as conexões explícitas entre comunidade de fala e nação tenham desaparecido da teorização linguística, enquanto a nostalgia pela comunidade, o impulso para unificar o mundo social, continua difundido. Mesmo quando a teoria social floresce, a linguística formal recua ainda mais para o neuro-biologismo e a inteligência artificial, enquanto a sociolinguística em muitos lugares parece metodológica e teoricamente em uma calmaria.

Até aqui, tenho discutido a linguística da comunidade como um projeto utópico que postula mundos sociais unificados, idealizados. Não será completamente surpreendente descobrir que ela tem também suas versões distópicas, nas quais os mundos sociais são descobertos e então denunciados como claustrofóbicos e degradados. Tem havido, por exemplo, abordagens distópicas assim como utópicas sobre a fala das mulheres, sendo provavelmente a mais conspícua delas o trabalho inicial de Robin Lakoff, Language and Women's Place (1975). Learning to labour, de Paul Willis (1977), poderia ser visto como uma abordagem distópica da interação pedagógica. Talvez seja fecundo pensar na visão de Basil Bernstein sobre a linguagem da classe trabalhadora como uma abordagem distópica dentro da linguística da comunidade. Trabalhando dentro das normas da classe dominante, Bernstein constrói a vida da classe trabalhadora como uma distopia linguística cujo caráter interno explica a privação de direitos sociais da classe trabalhadora (Bernstein, 1971). Resulta um paradoxo: Labov, por estar trabalhando dentro da linguística da comunidade, sugere que o Inglês Negro não representa um problema; para Bernstein, por estar trabalhando dentro da linguística da comunidade, a cultura verbal da classe trabalhadora representa nada mais do que um problema. Como ocorre com a maioria dos argumentos distópicos, a solução que parece se seguir do argumento de Bernstein 
é a dissolução da subcomunidade, um movimento que transgride completamente o ideal de comunidade, e certamente enfurece suas/seus adeptas/os. (A crítica literária, incidentalmente, também tem sua distopia: ao redor do edifício do cânone nacional utópico se espalha o monstro da cultura de massa numa estranha gosma sempre em expansão...)

\section{EM DIREÇÃO A UMA LINGUÍSTICA DO CONTATO}

Venho sugerindo que a tendência a postular subgrupos sociais existindo separadamente uns dos outros dá origem a uma linguística que busca capturar identidade, mas não o caráter relacional da diferenciação social. Essa linguística ignora a extensão na qual grupos dominantes e dominados não são compreensíveis separados uns dos outros e na qual suas práticas de fala são organizadas para encenar sua diferença e sua hierarquia. Esse é um ponto que Noelle Bisseret Moreau tem assumido (Moreau, 1984). Alegando que "as dissimilaridades entre as práticas linguísticas são significativas apenas à luz da organização social [total]", Moreau argumenta que "cada classe fala ela mesma de acordo com o mesmo referencial oculto. Esse referencial social é o grupo dominante... porque o referencial social é o mesmo para todas as classes, práticas linguísticas de classe não são homogêneas e essa não-homogeneidade é necessária para a dominação" (p. 59-60). Temos aqui, acredito, um estilo um pouco diferente de imaginar uma comunidade de fala. Em situações de dominação, na visão de Moreau, a heterogeneidade linguística é produzida pela homogeneidade do referencial social compartilhado (ou ideologia dominante). Dentro dessa perspectiva, os códigos, langues e competências postulados pela linguística da comunidade são corporificações desse referencial social compartilhado em relação ao qual todas as mensagens, paroles ou desempenhos situam-se a si mesmos. (O mesmo seria verdadeiro para textos literários canonizados.)

A visão de Moreau sugere uma linguística um pouco diferente. Os grupos dominados, na visão dela, são forçados ao que chama de subjetividade dividida, porque são obrigados a simultaneamente identificarem-se com o grupo dominante e dele se dissociarem. ${ }^{3} \mathrm{O}$ discurso desses grupos, consequentemente, é tanto distinto como permeado pelo do grupo dominante, como Moreau documenta a partir de entrevistas com mulheres e estudantes universitárias da classe trabalhadora em Paris. Moreau é, assim, capaz de sair de uma ideologia da autenticidade e de ver a

3 Aqui é lembrado o conceito de "dupla consciência" de W.E.B. Dubois, desenvolvido em seu clássico Souls of Black Folk. 
diferenciação social relacionalmente. Esse movimento, por sua vez, torna possível uma postura crítica mais efetiva na qual a forma como a linguagem produz dominação pode ser abordada.

Entretanto, o comprometimento de Moreau com o conceito de um referencial social unificado, dominante, continua a amarrá-la à linguística da comunidade. Ao fim, o argumento dela coincide com o de Bernstein ao ver as classes subordinadas apenas em termos de sua suposta falta daquilo que a classe governante supostamente tem - no caso de Moreau, uma subjetividade unificada e um discurso unificado para acompanhá-la. É sintomático que a análise de Moreau, como a de Labov, apoie-se em entrevistas formais nas quais o próprio processo de entrevista não é examinado. As afirmações das/os entrevistadas/os são tratadas como autorrepresentações neutras e nenhuma questão é gerada sobre a forma como a entrevista em si mesma poderia estar restringindo as/os entrevistadas/os a se apresentarem em termos do discurso da subjetividade unificada. A solução social que se segue do argumento de Moreau reafirma a comunidade: a/o dominada/o, ela diz, deve encontrar uma lógica distinta da sua própria para "interpretar sua condição social" (p. 60), ou seja, uma maneira de unificar seu mundo social. Como na visão de Jürgen Habermas, o único signo seguro de uma sociedade não hierárquica seria a completa homogeneidade linguística (HABERMAS, 1984).

Todavia, o argumento de Moreau oferece um ponto de entrada para se pensar sobre tipos de linguística que podem começar onde para a linguística da comunidade. A desconstrução muito nos ensinou sobre a necessidade de descentralizar as tendências centrífugas e homogeneizantes do pensamento ocidental, não porque sejam falsas, mas porque são limitadas de formas que elas mesmas não podem reconhecer. Imagine, então, uma linguística que descentralizasse a comunidade, que colocasse em seu centro a operação da linguagem através das linhas de diferenciação social; uma linguística que focalizasse os modos e zonas de contato entre grupos dominantes e dominados, entre pessoas de diferentes e múltiplas identidades, falantes de diferentes línguas; que focalizasse o modo como essas/es falantes se constituem umas/uns às/aos outras/os relacionalmente e na diferença, como encenam diferenças na língua. Chamemos esse empreendimento de uma linguística do contato, um termo ligado à noção de Jakobson de contato como um componente de eventos de fala e ao fenômeno das línguas de contato, um dos desafios mais bem reconhecidos para a sistematizadora linguística do código. Não é um termo satisfatório, particularmente porque atrai suas próprias conotações utópicas, mas que seja suficiente por enquanto. 
Para dar um exemplo altamente contrastivo de como essa linguística do contato poderia olhar para o mundo, deixe-me ilustrá-la com o caso muito tenso, embora pertinente, do apartheid sul-africano. Brancas/os ocidentais são encorajadas/os a pensar sobre o apartheid em termos da segregação de brancas/os e negras/os. Essa é a forma como a imprensa ocidental predominantemente o retrata ${ }^{7}$, justapondo fotos de Soweto ou dos chamados bantustões com fotos dos subúrbios de luxo brancos. Essa também é a forma como o apartheid pede para ser compreendido, a forma como se representa para si mesmo - como separação, isolamento. Linguisticamente, invoca um mundo no qual brancas/os falam com brancas/os, em africânder ou inglês, e negras/os falam com negras/os, em zulu, xhosa ou em uma das muitas outras línguas.

A imagem muda um pouco, entretanto, se você pensa sobre o apartheid como se referindo a formas particulares de conexão entre brancas/os e negras/os, como um sistema no qual elas/es não estão de modo algum separadas/os, mas continuamente na presença e no contato umas/uns com as/os outras/os, em locais de trabalho, nos negócios, ao lidar com o Estado, através de organizações religiosas, nos procedimentos de vigilância, através da escrita de muitos tipos. Tal perspectiva coloca em primeiro plano diferentes dimensões da tessitura vivida da sociedade do apartheid. Vê o apartheid como atividade, algo que as pessoas estão fazendo, algo encenado através de práticas nas quais diferença e dominação são continuamente produzidas no conflito. Quando as zonas de contato são centralizadas, pode-se ver, por exemplo, a enorme significância do trabalho doméstico na estratificação social radical, do fato de que, no caso da África do Sul, em quase toda família branca vive ao menos uma mulher trabalhadora negra, cujas obrigações incluem o cuidado e a socialização de crianças brancas. Pode-se começar a indagar como através dessas interações, através dessas relações ao mesmo tempo íntimas e impiedosamente exploradoras, o apartheid é encenado, reproduzido e aberto à mudança. Pode também se perguntar como o apartheid é diferentemente vivido por crianças, mulheres e homens.

Tal pode ser a perspectiva da linguística do contato, uma linguística que colocasse no seu centro os trabalhos de linguagem através, e não dentro dos limites, das linhas de diferenciação social de classe, raça, gênero, idade. Como meu exemplo sugere, é como um projeto crítico que estou discutindo a linguística aqui, isto é, como um projeto planejado para informar uma práxis acadêmica crítica. No caso do que veio a ser chamado "linguística crítica" (FOWLER et al, 1979), o projeto é produzir conhecimento crítico sobre os funcionamentos da dominação e da desumanização, de um lado, e das práticas igualitárias e de melhoria de vida, de outro. Como Frederic Jameson nos ensinou (JAMESON, 1981), a utopia tem um lugar nesses projetos críticos. Ao mesmo tempo, gostar-se-ia de evitar, no caso de uma 
linguística do contato, um impulso utópico de mostrar alegremente toda a humanidade em contato tolerante e harmonioso através de todas as linhas de diferença, ou um impulso distópico de lamentar um mundo homogeneizado pela mídia ocidental ou dirigido somente por mal-entendidos ou más intenções.

Tenho falado de uma linguística do contato em termos hipotéticos, mas é claro muitas/os leitoras/es já sabem de linguistas, etnógrafas/os, sociólogas/os e críticas/os literários que estão fazendo trabalhos deste tipo que estou descrevendo. Gostaria de usar meus poucos últimos parágrafos para mencionar alguns exemplos de trabalhos nas áreas da fala, da escrita, e do estudo literário que são pertinentes para uma linguística do contato. Essa enumeração se pretende apenas ilustrativa, e de modo algum programática. Não coincidentemente, é composta principalmente de trabalhos em estudos culturais e etnográficos em vez de em linguística convencional. Os exemplos vêm sobretudo da zona de contato na qual tenho um interesse acadêmico pessoal, a saber, as fronteiras do colonialismo europeu, em que as limitações de uma linguística da comunidade são talvez mais marcantes.

No caso da escrita, uma linguística do contato se interessará pelas condições em que a literatura é ensinada, por quem, através de quais instituições, quais textos, e em qual língua. Pensa-se aqui no trabalho de Elinor Ochs e Alessandro Duranti (1981) sobre o ensino de literatura na Nova Guiné, por exemplo. Segundo, em que ponto a escrita entra em ação nas relações de dominação, ou relações entre estados e cidadãs/aos? Como isso é assimilado? O trabalho de Shirley Heath (1983) sobre processamento oral de textos escritos numa pequena comunidade do sul toca nessas questões, assim como o estudo de Homi Bhabha (1985) sobre a renegociação oral da doutrina bíblica na Índia do século XIX.

Uma linguística do contato se interessará profundamente por processos de apropriação, penetração e cooptação da língua de um grupo pela outra - e pelo se ou como distinguir entre esses três tipos de contato. Um exemplo pertinente é o mencionado anteriormente, do falante negro de classe média, visto por Labov como copiando o inglês branco, e por Silverman e Torode como apropriando e intervindo no inglês branco. Essas são as questões que Silverman e Torode (1980) começaram a resolver com seu conceito de interrrupção.

Na escrita, Johannes Fabian (1985) tem estudado o uso de termos do Swahili em dois relatos de viagem europeus sobre a África oriental. Ele concluiu que essa apropriação mediou uma contradição para os escritores europeus entre a necessidade de usar dadas formas do discurso para uma audiência doméstica, e a necessidade de capturar a iminência e o choque da experiência de contato. Como, imagina-se, essa prática se parece do ponto de vista das/os falantes de Swahili? Em 
veio parecido, Vicente Rafael (1984) tem examinado os dilemas discursivos das autoridades religiosas espanholas ao introduzirem o cristianismo nas Filipinas. De um lado, fornecer análogos Tagalog para termos cristãos como "obrigação" ou "pecado" inevitavelmente significava incorporar ideologias indígenas que conflitavam com o cristianismo; de outro lado, simplesmente introduzir termos espanhóis nos textos Tagalog como itens "intraduzíveis" significava que conceitos-chave existiam como significantes flutuantes para os quais as/os falantes Tagalog poderiam atribuir seus próprios significados. Dentro e entre línguas, esses tipos de interpenetrações e apropriações são tão comuns que, ao contrário da reivindicação de Moreau (1984), o mundo de ninguém será considerado linguística ou subjetivamente homogêneo, nem mesmo o da classe dominante. Quando visto como um lugar de reprodução social e luta, a língua não pode ser imaginada como unificada.

Como os exemplos que eu esbocei sugerem, uma linguística do contato tomaria por certo o muito debatido deslize dos significantes, e ficaria muito mais preocupada, como estudiosas/os de línguas de contato são, com as dimensões improvisadas da construção do significado (Quando me foi dito por um/a habitante de Glasgow que certamente ela/e aproveitaria um "pulôver de lã" comigo numa visita a Glasgow, eu não precisei determinar o que "pulôver" significava para meu/minha interlocutor/a para saber (a) que não significa o que significa no meu próprio uso e (b) que eu deveria ir preparada para um clima frio).

De igual significado para uma linguística do contato é o fenômeno imensamente espalhado do bilinguismo, menos como um atributo de um/a falante do que como uma zona para elaborar os significados sociais e encenar as diferenças sociais. No sudoeste americano, um anglo que se dirige a um/a falante nativo/a do espanhol em espanhol quase sempre receberia invariavelmente uma resposta em inglês - a/o falante de língua minoritária usa a língua dominante para rejeitar a tentativa da/o falante da língua majoritária de unificar o mundo social. Uma dimensão bastante diferente do bilinguismo é discutida no trabalho de Braj Kachru sobre o fenômeno do "inglês internacional" que, ele argumenta, está criando elites em outros países, que são então hábeis em erigir barreiras linguísticas dentro de suas próprias sociedades e desenvolver práticas sociais com base no inglês que encenam e reproduzem seus privilégios. Aqui a segunda língua torna-se o único instrumento a criar nova estratificação social (KACHRU, 1984).

Para uma linguística do contato, a distinção entre a produção e a recepção da fala é suscetível de ser de muito maior importância do que para a linguística da comunidade. Para uma linguística do contato, é de grande interesse que pessoas possam geralmente entender muito mais variedades de discurso ou mesmo de línguas 
do que elas podem produzir ou entendê-las melhor do que elas podem produzi-las. O que Bernstein chamaria de falantes de "código restrito" necessariamente têm competências extensivas em "códigos elaborados", pelo menos na recepção final, competências que elas/es desenvolvem em negociações contínuas com códigos elaborados nos locais de trabalho, em instituições educacionais, na mídia, na participação política ou religiosa, negociações com o estado e assim por diante. Qual a natureza dessas competências, e como estão engajadas na reprodução das relações de classe? Do mesmo modo, falantes brancas/os de inglês nos Estados Unidos adquirem graus de competência de recepção para o inglês negro, um fenômeno que se pode levar em conta a fim de entender a cooptação da cultura negra na América, ou a possibilidade política de um Jesse Jackson, ou os limites dessa possibilidade política.

Como se estuda a variabilidade interna da recepção, o fato, por exemplo, de que mulheres e homens aprendem a escutar diferentemente, com mulheres altamente treinadas a segundas intenções, a olhar para subtextos emocionais que divulgariam a necessidade não dita a ser satisfeita, o desejo a ser preenchido? Eu penso aqui no trabalho de Tanya Modleski sobre novelas televisivas (MODLESKI, 1981).

Finalmente, há obviamente uma agenda para a crítica literária aqui. Um item principal é a gama de fenômenos sendo estudados agora sob a rubrica de "discurso colonial", e o "discurso sobre o Outro". Outro é o que Ronald Carter (1986) e outros referem como literaturas de contato, literaturas em línguas europeias produzidas fora da Europa e da América do Norte. Como sociedades pós-coloniais estão às voltas com os legados culturais e literários do ocidente? Um fenômeno relacionado é a emergência atual das culturas acadêmicas e literárias transnacionais que podem quase instantaneamente trazer García Márquez, ou o pós-modernismo, ou a linguística da escrita, às bocas das pessoas em todo o planeta. Tais culturas deram origem a elites acadêmicas e literárias globais, que, para retornar aos termos de Benedict Anderson, provavelmente precisam ser imaginadas em um estilo bem diferente da fraternidade soberana e horizontal da comunidade. ${ }^{4}$

Tais desenvolvimentos criam a necessidade de críticas/os treinadas/os na recepção de trabalhos não ancorados em categorias nacionais. Há filmes como O Beijo da Mulber Aranba, feito por um brasileiro a partir de um romance de um argentino vivendo no exílio, usando atrizes e atores norte-americanos e latino-americanos, as

4 Dados os comentários de Anderson sobre o romance, vale a pena notar que a elite acadêmica internacional tem recentemente começado a aparecer como um sujeito de romances tais como aqueles de David Lodge e Marilyn French. Seria interessante examinar se o romance acadêmico representa uma tentativa de imaginar essa formação transnacional como uma comunidade no sentido de Anderson, ou se sua emergência reflete uma mudança no romance para além do modelo de comunidade. 
línguas espanhol, inglês e português, filmado no Brasil e (eu acho) no México, destinado a ser lançado no exterior com especial atenção ao grande público falante de espanhol e homossexual nos Estados Unidos e à crise na América Central. Ou, para tomar um exemplo mais perturbador, que tal o filme sul-africano Os deuses devem estar loucos, que se tornou um sucesso de vendas mesmo no auge do sentimento anti-apartheid? Como esse filme brilhantemente conseguiu o empacotamento da política do apartheid de maneira a neutralizar o senso crítico de praticamente todo o público americano do filme? O que ele dizia que as/os brancas/os ocidentais queriam ouvir? Como esse filme colocou as/os ocidentais brancas/os em uma categoria unificada?

Mesmo que dignitários nacionais se juntem em torno de suas estátuas e falem através das ondas em línguas nacionais para imaginar fraternidades nacionais, textos estão aparecendo em seu próprio meio, o que deve confundi-los. Por exemplo, um livro chamado The Golden Gate recentemente desfrutou de imenso sucesso nos Estados Unidos. É um romance cômico-sentimental sobre a Califórnia, escrito por Vikram Seth, um Indiano do Leste, ex-economista formado em Oxford que estudou por muitos anos na China. O romance é escrito em versos, inspirado, de acordo com o autor, na tradução para o inglês, feita por Charles Johnston, do livro Eugene Onegin de Pushkin. É um trabalho de literatura americana? Alguém poderia encontrar um exemplo mais claro da transnacionalização da cultura? Ao lado do romance em versos de Seth, apareceu um livro chamado Shallow Graves (LARSEN \& NGA, 1986), um trabalho autobiográfico de duas mulheres, uma jornalista americana e uma trabalhadora de escritório vietnamita, que se conheceram no Vietnã e reestabeleceram sua relação nos Estados Unidos. Também é escrito como um romance em versos, em inglês, seguindo uma forma vietnamita chamada truyen. Tais novas formas, novos desafios para o entendimento linguístico, cultural e crítico, vão continuar a aparecer e a convocar nossas capacidades como linguística e crítica. Tais desafios somente podem ser ignorados ou mistificados por uma linguística da comunidade, cuja visão de linguagem está ancorada numa visão normativa de um mundo social unificado e homogêneo. É difícil abandonar o enorme conforto mental dessa visão. Mas vale a pena desistir, na esperança de ganhar uma linguística e uma crítica cujo engajamento com o mundo social não seja restrito à utopia.

\title{
REFERÊNCIAS BIBLIOGRÁFICAS
}

\author{
ALLEN, L. (1985). Liberty.
}

ANDERSON, B. (1983). Imagined communities: reflections on the origin and spread of nationalism. London. 
BACH, K.; HARNISH, R. M. (1980). Linguistic communication and speech acts. Cambridge, MA. BERNSTEIN, B. (1971). Class, codes and control. London.

BHABHA, H. (1985). Signs taken for wonders. Critical inquiry, v. 12, n. 1, pp. 144-164.

CARTER, R. (1986). A question of interpretation: an overview of some recent development in stylistics. In: D'Haen, T. (ed.). Linguistics and the study of literature. Amsterdam, pp. 7-26.

CICOUREL, A. (1982). Language and belief in a medical setting. In: Byrnes, H. (ed.). Contemporary perceptions of language: interdisciplinary dimensions. Georgetown University Round Table, Washington, pp. 48-78.

COULTHARD, R. M. (1977). In introduction to discourse analysis. London.

COULTHARD, R. M.; MONTGOMERY, Martin (ed.). (1981). Studies in discourse analysis. London.

FABIAN, J. (1985). Language on the road: notes on Swabili in two nineteentb-century travelogues. Hamburg.

FISH, S. (1980). Is there a text in this class? Cambridge, MA.

FOWLER, R. et al. (1979). Language and control. London.

GRICE, H. P. (1975). Logic and conversation. In: Cole, P.; Morgen (ed.). Syntax and semantics, v. 3: Speech Acts, New York, pp. 41-58.

HABERMAS, J. (1984). The theory of communicative action. v. 1. Trad.: Thomas MacCarthy, Boston.

HALLIDAY, M. A. K. (1977). Explorations in the functions of language. New York.

HALLIDAY, M. A. K; HASAN, R. (1976). Cobesion in English. New York.

HARDING, S. (1975). Women and words in a Spanish village. In: Reiter, R. (ed.). Toward an anthropology of women. Monthly Review Press.

HEALTH, S. (1983). Ways with words. Cambridge.

HEBDIGE, D. (1979). Subculture: the meaning of style. London.

HIATT, M. P. (1977). The way women write. New York.

HYMES, D. (1974). Foundations in Sociolinguistics: an etbnograpbic approach. Philadelphia.

JAMESON, F. (1981). The political unconscious: narrative as a socially symbolic act. New York.

KACHRU, B. (1984). The alchemy of English: social and functional power of non-native varieties. In: Kramarae, Cheris et al. (eds.). Language and power. Beverley Hills, pp. 176-193.

KEY, M. R. (1977). Male/Female language. New Jersey.

KRAMARAE, C.; SCHULZ, M.; O’BARR, W. (eds.). (1984). Language and power. Beverley Hills.

LABOV, W. (1972). Language in the inner city. Philadelphia.

LAKOFF, R. (1975). Language and women's place. New York.

LARSEN, W. W.; NGA, T. T. (1986). Shallow graves. New York.

MILLER, C.; SWIFT, K. (1977). Words and women. New York. 
MODLESKY, T. (1981). The art of being off-center: daytime television and women's work. Tabloid, n. 4, pp. 18-24.

MOREAU, N. B. (1984). Education, ideology and class/sex identity. In: Kramarae, C.; Schulz, M.; O’Barr, W. (eds.). Language and power. Beverley Hills, pp. 43-61.

OCHS, E.; DURANTI, A. (1981). Literacy in a Samoan village. Lecture presented at Conference on Literacy and Language Use, 12-14 November, University of Southern California, Los Angeles.

PRATT, M. L. (1983). Interpretative strategies/strategic interpretations: Anglo-American reader-response criticism. Boundary 2, fall. [Reprinted In: Arac, J. (ed.). Postmodernism and Politics. Manchester, 1986, pp. 26-54].

PRATT, M. L. (1986). Ideology in speech act theory. Poetics today, v. 7, n. 1, pp.59-72.

RAFAEL, V. (1984). Contracting Christianity: conversion and translation in early Tagalog colonial society. PhD Dissertation. Cornell University, Ithaca, New York.

SETH, V. (1986). The Golden Gate. New York.

SILVERMAN, D.; TORODE, B. (1980). The material word. London.

SPENDER, D. (1985). Man made language. London.

STEEDMAN, C.; URWIN, C.; WALKERDINE, V. (eds.). (1985). Language, gender and childhood. History Workshop Series. London.

STUBBS, M. (1983). Discourse analysis: the sociolinguistic analysis of natural language. Oxford.

THORNE, B.; HENLEY, N. (eds.). (1975). Language and sex: difference and dominance. Rowley, Massachusetts.

THORNE, B.; KRAMARAE, C.; HENLEY, N. (eds.). (1983). Language, gender, and society. Rowley, Massachusetts.

WILLIS, P. (1977). Learning to labour: bow working class kids get working class jobs. Farnborough.

Recebido: 01/10/2013

Aceito: 23/10/2013 
